Agric. Biol. Chem., 42 (2), 253 258, 1978

\title{
Effects of Phenolic Compounds on the Mitochondrial Phenol Oxidase of Spinach Leaves ${ }^{\dagger}$
}

\author{
Yoshiaki Oda, Shoichi OH-E, Genya SAIto* \\ and Hiroyuki MATSUOKA \\ Department of Agricultural Chemistry, Faculty of Agriculture, \\ Yamagata University, Tsuruoka, Yamagata \\ Received June 8, 1977
}

\begin{abstract}
When a solution of purified mitochondrial phenol oxidase from spinach leaves has been stored frozen, the Michaelis constant decreased with the lapse of time after thawing of the frozen enzyme solution, and reached a constant value, $4.7 \times 10^{-3} \mathrm{M}$, in $2.5 \mathrm{hr}$. Immediately after thawing of the frozen enzyme solution, the oxidation of catechol catalyzed by the phenol oxidase was competitively inhibited by $p$-substituted phenols. The enzyme kept for $2.5 \mathrm{hr}$ after thawing was allosterically inhibited by $p$-substituted phenols. These results suggest that the conformation of the enzyme changes with the lapse of time after thawing. However, a differential spectral study of the enzyme immediately after thawing and that $2.5 \mathrm{hr}$ after thawing did not indicate any appreciable change of optical density in the range of $260 \sim 350 \mathrm{~nm}$.
\end{abstract}

Phenol oxidase (o-diphenol: oxygen oxidoreductase, 1.10.3.1, EC) is widely distributed in the plant kingdom, and purification and properties of the enzyme have been investigated by many workers. Mino and Hattori ${ }^{1 /}$ described the occurrence of the enzyme in chloroplasts from green leaves of various plant species, and many studies have been carried out on intracellular distribution, purification and characterization of the enzyme of various plants. However, few studies on purification and properties of the enzyme in subcellular fraction have been known. ${ }^{2 \sim 47}$

In our laboratory, phenol oxidase was purified from a mitochondrial fraction of spinach leaves, and some properties of the purified enzyme was reported. ${ }^{5}$ In the report, it was indicated that the enzyme was inhibited by some phenolic compounds.

Many investigators have found that phenol oxidases from several kinds of sources were

\footnotetext{
+ Studies on Phenol Oxidase in Green Leaves. Part II.

This work was presented in part at the 50th Meeting of the Agricultural Chemical Society of Japan, Sapporo, July 1975.

* Present address: Upland Forming Division, Hokkaido National Agricultural Experiment Station, Memuro, Hokkaido.
}

inhibited by substituted cinnamic acids, and that the inhibition obeyed Michaelis-Menten's mechanism..$^{6 \sim 10)}$ In this paper, we describe how the phenol oxidase purified from a mitochondrial fraction of spinach leaves is inhibited competitively by 4-substituted catechols and allosterically by $p$-substituted phenols, and how the types of the inhibition change with the lapse of time after thawing of the enzyme solution stored frozen. Based on these results, the possibility of conformational change of this enzyme is discussed.

\section{MATERIALS AND METHODS}

1. Plant material. Spinach (Spinacia oleraceae L.) was obtained in the market between April and July. Leaves were removed from the plant and stored at $5^{\circ} \mathrm{C}$ overnight after washing.

2. Preparation of mitochondrial fraction. One hundred grams of the spinach leaves were homogenized with $200 \mathrm{ml}$ of $0.1 \mathrm{M}$ Tris- $\mathrm{HCl}$ buffer, $\mathrm{pH} 7.5$, containing $0.25 \mathrm{M}$ sucrose, for $30 \mathrm{sec}$ with a Universal Homogenizer (Nihon Seiki Co.). The homogenate was filtered through four pieces of gauze, and the filtate was centrifuged at $2000 \times g$ for $10 \mathrm{~min}$. The supernatant was then centrifuged at $10,000 \times g$ for $20 \mathrm{~min}$. The pellet was suspended in $0.35 \mathrm{M}$ sucrose solution, and the suspension was centrifuged at $10,000 \times g$ for $20 \mathrm{~min}$. After the procedure was repeated three times, the pellet 
was suspended in $1 / 20 \mathrm{M}$ phosphate buffer, pH 7.5. The suspension was used as the mitochondrial fraction. All procedures were carried out at $0^{\circ} \mathrm{C} \sim 5^{\circ} \mathrm{C}$.

3. Preparation of phenol oxidase. To 16 parts of cold acetone $\left(-20^{\circ} \mathrm{C}\right)$, the mitochondrial fraction was added. Precipitate was collected by centrifugation, and the pellet was suspended in cold acetone. Insoluble matter was collected by centrifugation. The procedure was repeated until the acetone layer became colorless. The pellet was dried in vacuo to make acetone powder. Phenol oxidase was extracted from the acetone powder with $1 / 20 \mathrm{~m}$ phosphate buffer, $\mathrm{pH} 7.5$, and purified by gel-filtration on Sephadex G-75, ion-exchange chromatography on P-cellulose and on DEAE-cellulose, successively. The details of the procedure were described previously. ${ }^{5 /}$ A phosphate buffer solution of the purified phenol oxidase was obtained. The purified enzyme was found electrophoretically homogeneous on cellulose acetate gel (Chemetron Co.). ${ }^{5)}$

The purified enzyme solution was stored frozen $\left(-15^{\circ} \mathrm{C}\right.$ ) after dialysis against $1 / 20 \mathrm{M}$ phosphate buffer, $\mathrm{pH}$ 7.0. The concentration of the enzyme solution was about $10 \mathrm{mg} \%$ or below. Prior to use as a sample, the frozen solution was kept at room temperature for $2.5 \mathrm{hr}$ after thawing unless otherwise stated.

4. Determination of phenol oxidase activity

i) Oxygen electrode method. To $2.2 \mathrm{ml}$ of $1 / 20 \mathrm{M}$ phosphate buffer, pH 7.0, containing $5 \mu$ moles of the substrate, was added $0.5 \mathrm{ml}$ of the enzyme solution. Oxygen consumption by oxidation of the substrate was electrically measured with a Bioxygraph (Kyusui Kagaku Co.). The reaction was started by the addition of the enzyme after pre-incubation of the substrate in buffer solution for $10 \mathrm{~min}$. The reaction was carried out at $30^{\circ} \mathrm{C}$. The amount of oxygen consumption was calculated from the initial velocity and expressed in $\mu$ moles. The amount of oxygen dissolved in 1 liter of water equilibrated with air at $30^{\circ} \mathrm{C}, 235 \mu$ moles, ${ }^{11}$ ) was used as the standard.

ii) Colorimetric method. To $2.9 \mathrm{ml}$ of $0.022 \mathrm{M}$ phosphate buffer, $\mathrm{pH} 7.0$, containing $5 \mu$ moles of substrate, was added $0.1 \mathrm{ml}$ of enzyme solution. The increase of optical density at $475 \mathrm{~nm}$ due to the oxidation of the substrate was measured. The reaction was carried out in a cuvette having light path of $10 \mathrm{~mm}$ at $30^{\circ} \mathrm{C}$.

5. Chemicals. $\quad \beta$-(4-Hydroxyphenyl)-propionic acid and $\beta$-(3,4-dihydroxyphenyl)-propionic acid were prepared from $p$-hydroxycinnamic acid and 3,4-dihydroxycinnamic acid, respectively, by catalytic reduction in the presence of palladium-active carbon catalyst (Nikki Chemical Co.). These products were recrystallized from water. The melting points of these compounds agreed with those in the literature. ${ }^{12,13)}$ P-Cellulose and DEAE-cellulose were supplied from Serva Co. and Midori-Jûji Co., respectively.

\section{RESULTS AND DISCUSSION}

\section{Michaelis constants of the phenol oxidase} for some catechol derivatives

The Michaelis constant for catechol obtained by the oxygen electrode method was compared with that by the colorimetric method. As shown in Fig. 1, values calculated from double reciprocal plots for the two methods, despite the difference in principle, were practically identical. Two steps are involved in the oxidation of catechol by phenol oxidase, the oxidation of catechol into $o$-quinone and the color development. The colored compound formation is a complex reaction involving polymerization of the oxidation products. However, this result suggests that the oxidation of catechol by the phenol oxidase can be regarded

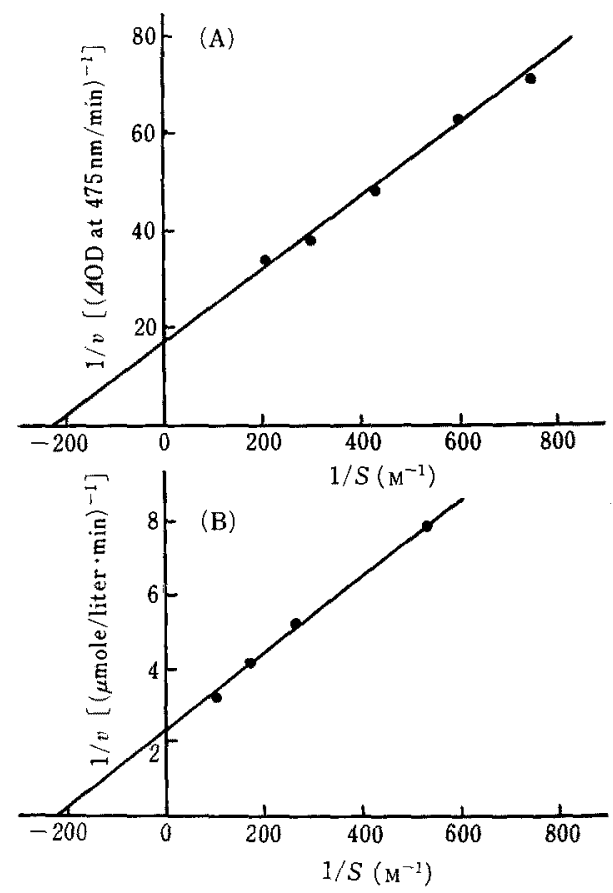

Fig. 1. Double Reciplocal Plots of the Oxidation of Catechol Determined by the Colorimetric and the Oxygen Electrode Methods.

The conditions are described in MATERIALS AND Methods. (A): Colorimetric method; (B): Oxygen electrode method. 
as a relatively simple enzymic reaction.

Michaelis constants for some catechol derivatives were determined by the oxygen electrode method. The results are listed in Table I. The Michaelis constant of the phenol oxidase from a mitochondrial fraction of spinach leaves for catechol, $4.7 \times 10^{-3} \mathrm{M}$, is smaller than that of bean leaves' enzyme, $1.5 \times 10^{-2} \mathrm{M}^{14)}$ and larger than those of the tobacco root enzyme, $6.0 \times 10^{-4} \mathrm{M}^{15)}$ and the mushroom enzyme, $2.4 \times 10^{-4}$ M. $^{163}$

Among the 4-substituted catechols, chlorogenic acid, 3,4-dihydroxyphenylalanine (dopa), 3,4-dihydroxycinnamic acid (caffeic acid), $\beta$ (3,4-dihydroxyphenyl)-propionic acid were found to behave as substrates for the phenol oxidase, while 3,4-dihydroxyphenylacetic acid, 3,4-dihydroxybenzoic acid and 3,4-dihydroxybenzaldehyde were not oxidized by the enzyme. These results suggest that the structure of the side chain and, especially, the chain length affect affinity to the enzyme. Mayer ${ }^{17}$ reported that phenol oxidase from lettuce seeds could oxidize 3,4-dihydroxybenzaldehyde and 3,4-dihydroxybenzoic acid. Also, Coggon, Moss and Sanderson, ${ }^{18}$ and Takeo and Uritani ${ }^{19)}$ found that tea phenol oxidase could not oxidize chlorogenic acid. These reports may indicate that the substrate specificity of phenol oxidase can be traced to their sources.

\section{Inhibitory action of catechol derivatives}

As shown in Table I, some 4-substituted catechols were not oxidized by the phenol oxidase. As Bonner and Wildman ${ }^{20)}$ reported that 4-nitrocatechol was an inhibitor for phenol oxidase, the inhibitory effect of 4-substituted catechols on the mitochondrial phenol oxidase was presumed. Therefore, the effect of some 4-substituted catechols on the oxidation of catechol by the enzyme was studied. None of the 4-substituted catechols tested (Table II) were oxidized and inhibited the enzyme reaction competitively as shown in Fig. 2. As listed in Table II, the $K i$-values were about $1 / 10$ of the $K m$-value for catechol. This result suggests that the affinity of these inhibitors to the enzyme is stronger than that of the substrates.
Table I. Substrate Specificity of the Mitochondrial Phenol Oxidase of SPINACH LEAVES

\begin{tabular}{|c|c|c|}
\hline Substrate & $\begin{array}{c}\text { Relative } \\
\text { reaction } \\
\text { rate }\end{array}$ & $\left(\times 10^{-3} \mathrm{M}\right)$ \\
\hline Catechol & 100 & 4.7 \\
\hline Chlorogenic acid & 75 & 10 \\
\hline $\begin{array}{l}\text { 3,4-Dihydroxyphenyl- } \\
\text { alanine (Dopa) }\end{array}$ & 239 & 4.4 \\
\hline $\begin{array}{r}\text { 3,4-Dihydroxycinnamic } \\
\text { acid (Caffeic acid) }\end{array}$ & 65 & 38 \\
\hline $\begin{array}{l}\beta-(3,4-\text { Dihydroxyphenyl)- } \\
\text { propionic acid }\end{array}$ & 32 & 40 \\
\hline $\begin{array}{l}\text { 3,4-Dihydroxyphenylacetic } \\
\text { acid }\end{array}$ & 0 & \\
\hline 3,4-Dihydroxybenzoic acid & 0 & \\
\hline 3,4-Dihydroxybenzaldehyde & 0 & \\
\hline
\end{tabular}

Table II. $K i$-Values of Some 4-Substituted Catechols

\begin{tabular}{lc}
\hline \multicolumn{1}{c}{ Compounds } & $K i\left(\times 10^{-4} \mathrm{M}\right)$ \\
\hline 3,4-Dihydroxyphenylacetic acid & 8.8 \\
3,4-Dihydroxybenzoic acid & 67 \\
3,4-Dihydroxybenzaldehyde & 5.5 \\
Quercetin & 9.5 \\
Rutin & 14 \\
\hline
\end{tabular}

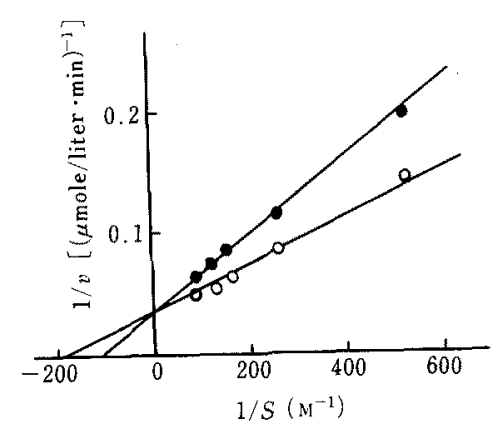

Fig. 2. Effect of 3,4-Dihydroxyphenylacetic Acid on the Oxidation of Catechol by the Phenol Oxidase. $\mathrm{O}-\mathrm{O}$, absence of 3,4-dihydroxyphenylacetic acid; - presence of $0.8 \mathrm{~mm} 3,4$-dihydroxyphenylacetic acid.

Lanzarini, Pifferi and Zamorani ${ }^{21 /}$ considered that in the sweet cherry phenol oxidase, substrates with electron-donating substituents, would more easily allow the formation of the enzyme-substrate complex and the enzyme should therefore have a greater activity against them. However, 3,4-dihydroxycinnamic acid has little substrate reactivity to the spinach 
leaves' mitochondrial phenol oxidase in spite of the presence of an electron-donating group at the 4-position. Moreover, 3,4-dihydroxybenzoic acid and 3,4-dihydroxybenzaldehyde are competitive inhibitors of the enzyme. The $K i$-value for the former is nearly equal to the $K m$-value for catechol, and the $K i$-value for the latter is smaller than that. This result may indicate that these two compounds have greater affinities to the phenol oxidase despite the presence of electron-attracting groups. Though both, the sweet cherry enzyme and the spinach leaves' mitochondrial enzyme, are copper enzymes, it is considered that the structure and/or the state of active sites of the two enzymes differ from each other (e.g. the optimum pHs of the enzymes were not identical). The difference in the oxidation rate of substrates may be due to the sources of phenol oxidase. ${ }^{22,237}$ Therefore, further studies may be required for obtaining the relations between structure of catechol derivatives and affinity to the phenol oxidase.

\section{Inhibitory effect of p-substituted phenols}

As shown in a previous paper, ${ }^{5)} p$-coumaric acid inhibited the oxidation of catechol by the spinach leaves' mitochondrial phenol oxidase. The plot of velocity $v s$. concentration of catechol in the presence of $p$-coumaric acid was a sigmoid curve as shown in Fig. 3. Hill's plot is shown in Fig. 4. Hill's coefficient, $n$, was calculated to be about 2 , and the plot of $1 / v$ vis. $1 /[S]^{2}$ was a straight line (Fig. 4). Inhibition of phenol oxidases from various kinds of plant tissues by $p$-coumaric acid has been reported by many workers, ${ }^{\beta \sim 10)}$ and the presence of two distinct binding sites on the enzymes (a catalytic site and an inhibitor site) has been suggested, although these enzymes did not appear to exhibit an allosteric type of inhibition. The results shown in Figs. 3 and 4 suggest that the mode of the inhibition of the mitochondrial phenol oxidase from spinach leaves by $p$-coumaric acid is an allosteric type, and the enzyme has at least two binding sites. $p$-Coumaric acid may bind to the catalytic site of the enzyme because of its structural similarity

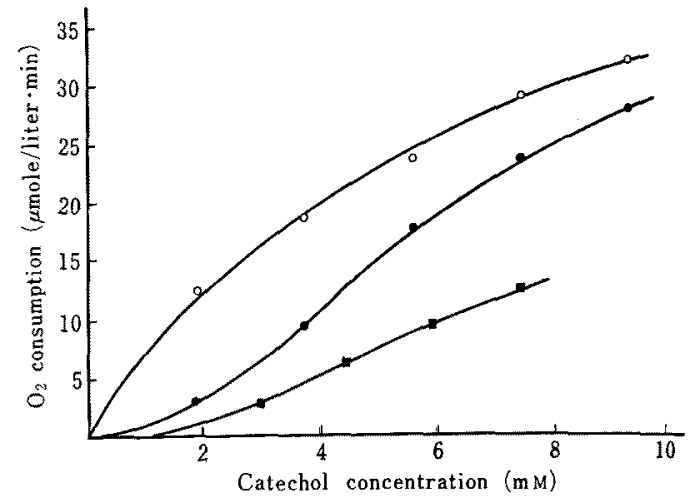

FiG, 3. Effect of $p$-Hydroxycinnamic Acid ( $p$ Coumaric Acid) on the Oxidation of Catechol.

$\mathrm{O}-\mathrm{O}$, absence of $p$-coumaric acid; -1 , presence of $0.92 \mathrm{~mm} p$-coumaric acid; $\mathbf{\square}-\mathbf{\square}$, presence of $3.7 \mathrm{~mm}$ p-coumaric acid.

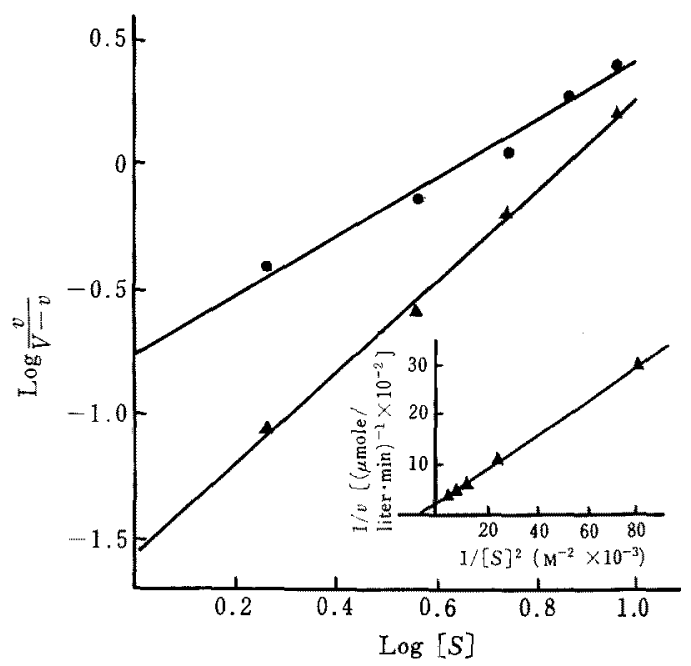

FIG. 4. Hill's Plot and $1 /[S]^{2}-1 / v$ Plot of the Oxidation of Catechol in the Presence of $p$-Coumaric Acid.

$\longrightarrow$, absence of $p$-coumaric acid; $\boldsymbol{\Lambda}-\mathbf{\Lambda}$, presence of $0.92 \mathrm{~mm} p$-coumaric acid.

to catechol. Therefore, the two binding sites may be identical (catalytic site).

Furthermore, the effects of some $p$-substituted phenols on the oxidation of catechol were investigated. In all the cases tested (Fig. 5), Lineweaver-Burk's plots were convex curves and the plots of $1 / v$ vs. $1 /[S]^{2}$ were straight lines as shown in Fig. 5. These results suggest that these compounds function in the same way as does $p$-coumaric acid. 


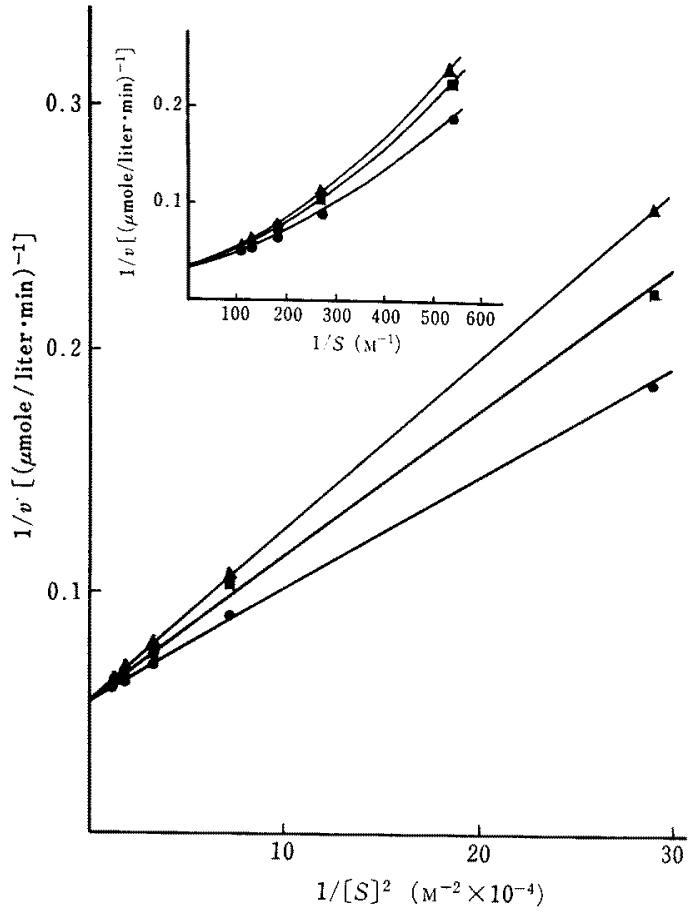

Fig. 5. $1 /[S]^{2}-1 / v$ Plot and Double Reciprocal Plot of the Oxidation of Catechol in the Presence of Some $p$-Substituted Phenols.

$\Delta-\mathbf{\Delta}$, presence of $0.8 \mathrm{mM} p$-cresol; $\mathbf{\square}-\mathbf{0}$, presence of $0.8 \mathrm{~mm} \beta$-(4-hydroxyphenyl)-propionic acid; presence of $0.8 \mathrm{~mm}$ tyrosine.

\section{Effect of time after thawing of the frozen enzyme solution}

It was reported by Dawson and Nelson ${ }^{2 * 3}$ that crystallized mushroom phenol oxidase was inactive just after dissolving in buffer solution, but the activity increased with the lapse of time. This fact suggests that the phenol oxidase slowly changed its conformation after dissolving in buffer solution. Lerner, Mayer and Harel ${ }^{25}$ ) found the occurrence of conformational change in grape catechol oxidase exposed to acid $\mathrm{pH}$ or urea for a short time. These results may indicate that phenol oxidases have a tendency to change their conformation under certain circumstances.

Changes in $\mathrm{Km}$-value with the lapse of time after thawing of the frozen enzyme solution were studied. As listed in Table III, the $\mathrm{Km}$ value for catechol decreased with the lapse of time after thawing and reached a constant value
Table III. Change in $K m$ Value with THE LAPSE OF TIME AFTER THAWING OF THE Frozen ENzyme Solution

\begin{tabular}{cc}
\hline $\begin{array}{c}\text { Time after thawing } \\
(\mathrm{hr})\end{array}$ & $K m\left(\times 10^{-3} \mathrm{M}\right)$ \\
\hline $0^{a)}$ & 20 \\
$0^{b)}$ & 13 \\
$0^{()}$ & 10 \\
2.5 & 4.7 \\
6 & 4.7 \\
\hline
\end{tabular}

a) Enzyme frozen for several days.

b) Enzyme frozen for $24 \mathrm{hr}$.

c) Enzyme frozen for $12 \mathrm{hr}$.

in $2.5 \mathrm{hr}$. The $K m$-value measured immediately after thawing may have a tendency to increase with the lapse of time when the enzyme solution is kept frozen (Table III). Further, the enzyme was competitively inhibited by $p$ coumaric acid immediately after thawing as shown in Fig. 6. These results suggest a change in the conformation of the enzyme with the lapse of time after thawing. However, a differential spectral study of the enzyme solution immediately after thawing and that after $3 \mathrm{hr}$ indicates that these two enzymes show the same spectrum in the range of 260 $350 \mathrm{~nm}$. Though this result suggests that the difference in conformation between the two enzymes is slight, further investigations are needed for detailed discussion of this matter.

It has been known that many phenolic com-

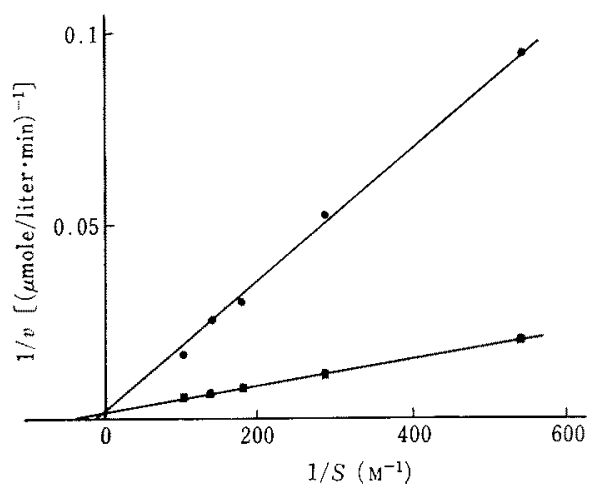

FIG. 6. Effect of $p$-Coumaric Acid on the Oxidation of Catechol by the Phenol Oxidase Solution Immediately after Thawing.

-n, absence of $p$-coumaric acid; $3.2 \mathrm{~mm}$ p-coumaric acid. 
pounds involving phenolic pigments exist in spinach leaves. Though, the state of the phenol oxidase in intact mitochondria is as yet unknown, the activity may probably be controlled by the phenolic compounds coexisting in vivo.

Acknowledgement. The authors wish to thank Professor Tadahiko Yasui for his encouragement throughout this work.

\section{REFERENCES}

1) Y. Mino and S. Hattori, Bot. Mag. Tokyo, 76, 1 (1963).

2) M. Sato, ibid., 81, 356 (1968).

3) E. Harel, A. M. Mayer and Y. Shain, Phytochemistry, 4, 783 (1965).

4) M. Sato and M. Hasegawa, ibid., 15, 61 (1976).

5) Y. Oda, T. Watanabe and S. Oh-e, Nippon Nôgeikagaku Kaishi, 47, 301 (1973).

6) A. R. Macrae and R. G. Duggleby, Phytochemistry, 7, 855 (1968).

7) N. de J. Rivas and J. R. Whitaker, Plant Physiol., 52, 263 (1974).

8) P. G. Pifferi, L. Baldassari and R. Cultrera, Plant Physiol., 25, 263 (1974).
9) J. R. L. Walker, Phytochemistry, 8, 561 (1969).

10) J. R. L. Walker and E. L. Wilson, J. Sci. Fd. Agric., 26, 1825 (1975).

11) R.W. Estabrook, "Methods in Enzymology," Vol. X, ed. by R.W. Estabrook and M.E. Pullman, Academic Press Inc., New York, N. Y., 1967, pp. 41.

12) C. Stöhr, Ann., d. Chem., 225, 62 (1884).

13) M. Bamberger, Monatsh. Chem., 12, 450 (1891).

14) D. Racusen, Can. J. Bot., 48, 1029 (1970).

15) E. C. Sisler and H. J. Evans, Plant Physiol., 33, 255 (1958).

16) J. L. Smith and R. C. Krueger, J. Biol. Chem., 237, 1121 (1962).

17) A. M. Mayer, Phytochemistry, 1, 237 (1962).

18) P. Coggon, G. A. Moss and G.W. Sanderson, ibid., 12, 1947 (1973).

19) T. Takeo and I. Uritani, Agric. Biol. Chem., 30, 155 (1966).

20) J. Bonner and S. G. Wildman, Arch. Biochem., 10, 497 (1946).

21) G. Lanzarini, P. G. Pifferi and A. Zamorani, Phytochemistry, 11, 89 (1972).

22) E. Harel and M. Mayer, ibid., 10, 17 (1971).

23) M. F. Roberts, ibid, 10, 3021 (1971).

24) H. R. Dawson and J. M. Nelson, J. Am. Chem. Soc., 61, 2949 (1939).

25) H. R. Lerner, A. M. Mayer and H. Harel, Phytochemistry, 11, 2415 (1972). 